OPEN ACCESS

Edited by:

Nicole J. Jaffrezic-Renault, Claude Bernard University Lyon 1,

France

Reviewed by:

Kohji Mitsubayashi,

Tokyo Medical and Dental University,

Japan

Eduardo Pinilla-Gil,

Universidad de Extremadura, Spain

*Correspondence:

Larisa Lvova

larisa.Ivova@uniroma2.it

Vito Lippolis

lippolis@unica.it

Specialty section:

This article was submitted to

Analytical Chemistry,

a section of the journal

Frontiers in Chemistry

Received: 17 March 2018

Accepted: 08 June 2018

Published: 28 June 2018

Citation:

Lvova L, Caroleo F, Garau A,

Lippolis V, Giorgi L, Fusi V, Zaccheroni N, Lombardo M, Prodi L, Di Natale $C$ and Paolesse R (2018) A

Fluorescent Sensor Array Based on Heteroatomic Macrocyclic

Fluorophores for the Detection of Polluting Species in Natural Water

Samples. Front. Chem. 6:258.

doi: 10.3389/fchem.2018.00258

\section{A Fluorescent Sensor Array Based on Heteroatomic Macrocyclic Fluorophores for the Detection of Polluting Species in Natural Water Samples}

\author{
Larisa Lvova ${ }^{1 *}$, Fabrizio Caroleo ${ }^{1}$, Alessandra Garau ${ }^{2}$, Vito Lippolis ${ }^{2 *}$, Luca Giorgi ${ }^{3}$, \\ Vieri Fusi ${ }^{3}$, Nelsi Zaccheroni ${ }^{4}$, Marco Lombardo ${ }^{4}$, Luca Prodi ${ }^{4}$, Corrado Di Natale ${ }^{5}$ and \\ Roberto Paolesse ${ }^{1}$ \\ ${ }^{1}$ Department of Chemical Science and Technologies, University "Tor Vergata", Rome, Italy, ${ }^{2}$ Dipartimento di Scienze \\ Chimiche e Geologiche, Università degli Studi di Cagliari, Monserrato, Italy, ${ }^{3}$ Department of Pure and Applied Sciences, \\ Università degli Studi di Urbino, Urbino, Italy, ${ }^{4}$ Dipartimento di Chimica "G. Ciamician" Università degli Studi di Bologna, \\ Bologna, Italy, ${ }^{5}$ Department of Electronic Engineering, University "Tor Vergata", Rome, Italy
}

The development of a novel all-solid-state optical sensor array based on heteroatomic macrocyclic fluorophores (diaza-crown ether, metallocorrole and pyridinophans) for the photographic analysis of liquid media, is presented. The sensitivity of the new optical system toward a number of different species (cations: $\mathrm{Li}^{+}, \mathrm{K}^{+}, \mathrm{Na}^{+}, \mathrm{NH}_{4}^{+}, \mathrm{Mg}^{2+}$, $\mathrm{Ca}^{2+}, \mathrm{Co}^{2+}, \mathrm{Cu}^{2+}, \mathrm{Zn}^{2+}, \mathrm{Cd}^{2+}, \mathrm{Pb}^{2+}$ and anions: $\mathrm{NO}_{2}^{-}, \mathrm{NO}_{3}^{-}, \mathrm{Cl}^{-}, \mathrm{Br}^{-}, \mathrm{HCO}_{3}^{-}$) was evaluated both in single selective sensor mode and in multisensory arrangement. The satisfactory PLS1 regression models between sensor array optical response and analyte concentration were obtained for $\mathrm{Cd}^{2+}, \mathrm{Cu}^{2+}, \mathrm{Zn}^{2+}$, and $\mathrm{NO}_{2}^{-}$ions in all the range of tested concentrations. Among these species the highest attention was focused onto detection of cadmium and nitrite ions, for which the detection limits, DL, estimated by $3 \sigma$ method were found $0.0013 \mathrm{mg} / \mathrm{L}$ and $0.21 \mathrm{mg} / \mathrm{L}$ respectively, and these values are lower than the corresponding WHO guideline values of $0.003 \mathrm{mg} / \mathrm{L}\left(\mathrm{Cd}^{2+}\right)$ and $2 \mathrm{mg} / \mathrm{L}\left(\mathrm{NO}_{2}^{-}\right)$. The suitability of the developed sensors implemented with familiar devices for signal acquisition (Light Emitting Diode, LED, as light source and a digital camera as a signal detector), and chemometric methods for data treatment to perform fast and low-cost monitoring of species under interest, in real samples of environmental importance, is demonstrated.

Keywords: macrocylic fluorophore, optical sensor, water pollutants, cadmium, nitrite

\section{INTRODUCTION}

The use of optical techniques and optical chemical sensors for a satisfactory solution of a wide range of analytical tasks is becoming nowadays more and more popular (Askim et al., 2013; Lu, 2014; Bonifazi and Serranti, 2016; Di Natale et al., 2016). The growing interest in optical sensors implementation is due to the improved sensitivity and fast response time of such devices, simplicity in their preparation, construction, and signal acquisition. In fact, modern optical sensors often 
do not require a sophisticated and high energy consuming hardware, no wire connections with the detector. Furthermore, the analytically useful signal of optical sensors can be registered even with simple wide-used electronic devices such as smartphones, or without any power supply in a "naked-eye" mode.

Among the optical detection techniques, fluorimetry is very attractive since it provides highly selective luminescence evaluation in a tunable emission range. Moreover, the optical chemical sensors based on fluorophores can be combined in sensor arrays and coupled with chemometric approach (Lvova et al., 2014), thus permitting the identification and quantitation of various analytes, such as natural water pollutants (Amatori et al., 2012; Bazzicalupi et al., 2013; Arca et al., 2014; Kang et al., 2014; Guanais Goncalves et al., 2016), toxins (Lvova et al., 2018), pesticides (Lei et al., 2016), explosives (Bolse et al., 2017; Zhu et al., 2017), agents hazardous for human skin (Moczko et al., 2016), forbidden additives and pathogens in beverages (Tan et al., 2014; Nishi et al., 2015; Han et al., 2016) and in foodstuffs (Lvova et al., 2015; Mungkarndee et al., 2015, 2016).

In particular, the accurate detection of inorganic contaminants, and heavy and transition metal ions is especially important, since these species present a severe impact and intrinsic risks for human health and environment (World Health Organization, 2017). The high amount of transition and heavy metals in environment causes their consequent accumulation in living beings, which could bring to intoxication and several serious pathologies in humans, including allergies, tumors, and genetic mutations (Vahter et al., 2002; Grigg, 2004; Lee et al., 2004). To protect humans against health risks caused by multimetal contamination, a careful monitoring of metals content in the environment is required, and the development of low cost and easy to handle devices for in-field evaluation of heavy metal pollution represents, therefore, a challenging task. The development of analytical systems based on optical sensors for analysis of heavy meal pollution is actively investigated (Wang et al., 2008; Niu et al., 2013; Xu et al., 2014; Liu et al., 2017). Thus, $\mathrm{Xu}$ et al. have reported a fluorescent sensor array (Singapore Tongue, SGT) based on N, N, N', N'-tetrakis(2-pyridylmethyl)ethylenediamine derivatives as a chelating site and quinoline, picoline and BODYPY fluorogenic fragments as signaling active unit, for rapid detection of heavy metal ions, such as $\mathrm{Hg}^{2+}$, $\mathrm{Fe}^{3+}, \mathrm{Cr}^{3+}, \mathrm{Zn}^{2+}, \mathrm{Cd}^{2+}, \mathrm{Cu}^{2+}$, and $\mathrm{Pb}^{2+}$ (Xu et al., 2014) able to discriminate the concentration-dependent patterns of tested metals. The "safe-zone" concept was developed, which permitted to distinguish the clean water samples from those contaminated with hazardous species with Principal Component Analysis (PCA) by means of developed SGT fluorescent sensor array. The sensing materials were placed in 96-well plate and illuminated with a UV lamp at $\lambda_{\text {ex }}=365 \mathrm{~nm}$, the array output was measured with a standard fluorimeter. Previously, the similar concept of fluorimetric analytical system development was employed by Wang and coauthors, who tested an array composed from 9 chemosensors, both commercially available or newly synthesized, all bearing in their structure aromatic signaling units, but having different coordination chemistry and different signaling schemes, for the discrimination of 10 metal cations: $\mathrm{Ca}^{2+}, \mathrm{Mg}^{2+} \mathrm{Hg}^{2+}$,
$\mathrm{Cd}^{2+}, \mathrm{Al}^{3+}, \mathrm{Co}^{3+}, \mathrm{Zn}^{2+}, \mathrm{Cu}^{2+}, \mathrm{Ni}^{2+}$, and $\mathrm{Ga}^{3+}$ (Wang et al., 2008). The possibility of metals qualitative identification by linear discriminant analysis (LDA) and quantitative analysis in the range of concentration from $1 \times 10^{-5}$ to $5 \times 10^{-3}$ $\mathrm{mol} / \mathrm{L}$ with $90 \%$ of accuracy was also demonstrated. Selective ligands were incorporated into poly(ether)urethane matrixes and deposited onto multi-well plate by ultrasonic drilling. The sensor arrays were excited with a broadband UV lamp and the array output was recorded with Kodak Image station (440CF). Liu et al. have proposed a competitive host-guest fluorophore array for the selective discrimination of several heavy metal ions, including lanthanide and actinide salts in aqueous solution. In this system the host-metal interactions resulted in both a fluorescence enhancement and quenching, thus improving its discriminatory properties. The fluorescence assay was performed on 96-well plates and the fluorophore signal was recorded in a Microplate Reader (Liu et al., 2017). Niu et al. have developed a fluorometric sensor array based on 12 different BODYPY (4,4-difluoro-4-bora-3a,4a-diaza-s-indacene) derivatives as optically active units and multi-pyridyl ligands as the metal-binding receptors for sensitive detection of eight heavy-metal ions such as $\mathrm{Hg}^{2+}, \mathrm{Pb}^{2+}, \mathrm{Cd}^{2+}, \mathrm{Co}^{2+}, \mathrm{Cu}^{2+}$, $\mathrm{Ni}^{2+}, \mathrm{Zn}^{2+}$, and $\mathrm{Ag}^{+}$(Niu et al., 2013). Hierarchical clustering analysis was used for metal ions discrimination and the correct discrimination was found for all ions in concentration down to $1 \times 10^{-7} \mathrm{~mol} / \mathrm{L}$. A UV LED array equipped with a $365 \mathrm{~nm}$ narrow band filter was used as excitation light source and Nikon D7000 digital camera served for visualization of the sensor output. The developed system was employed for the detection of metal ions in tap and marine water samples. Our group has developed optical sensor arrays for detection of diverse potential treats in water (Lvova et al., 2013; Guanais Goncalves et al., 2016) and investigated the possibility to employ a multi-transduction approach for monitoring natural waters pollution by transition metals (Lvova et al., 2015). Moreover, various modifications such as implementation of nanodots (Jing et al., 2017; Wu et al., 2017), graphene oxide (Liu et al., 2013), nanoparticles (Ambrosi et al., 2015; Peng et al., 2018), porous anodic aluminum oxide (Wang and Meng, 2017) or conjugated electrolytes (Wu et al., 2015) templates were employed in previously developed optical sensing systems in order to enhance the fluorescence signal, thus improving the identification of several heavy metal ions.

Very recently, an elegant approach employing a transparent bacterial cellulose nanopaper modified with ratiometric Carbon Dots/Rhodamine $\mathrm{B}$ probe for fluorescent and colorimetric analysis of heavy metal ions (i.e., $\mathrm{Hg}^{2+}, \mathrm{Pb}^{2+}, \mathrm{Cd}^{2+}, \mathrm{Fe}^{3+}$, $\mathrm{Cu}^{2+}$ ) as a model analytes, was reported (Abbasi-Moayed et al., 2018). The color emission changes of the developed array under UV irradiation were monitored visually by naked eye or a smartphone camera; the array signal outputs were analyzed with hierarchical cluster analysis (HCA) and LDA. The applicability of the developed system to identify heavy metal ions in water and fish samples was demonstrated.

However, only few examples of multisensory fluorescent systems for analysis of anions are reported (Anzenbacher et al., 2013; Lin et al., 2015; Pushina and Anzenbacher, 2017). Thus, for instance a fluorescent sensor array based 
on supramolecular metallogels for the identification of $\mathrm{CN}^{-}$, $\mathrm{SCN}^{-}, \mathrm{S}^{2-}$ and $\mathrm{I}^{-}$anions in water was reported by Lin et al. (2015). The sensor array realized the anion selective response properties by the competitive coordination to the special gelator compound, of different metal ions and anions. Pushina and Anzenbacher have employed six biguanide derivatives, S1-S6, as receptors for various anions (halides, carboxylates, phosphates) binding in paper-based fluorescencebased sensor array (Pushina and Anzenbacher, 2017). The array was prepared by printing hydrophobic barriers on paper; the solutions of sensors S1-S6 in DMSO were applied on the obtained microzone plates, and their fluorescence changes upon $365 \mathrm{~nm}$ excitation were recorded using an UV-scanner. The aqueous solutions of 11 different analytes were correctly identified with LDA analysis. Anzenbacher et al. have also reported an anion-sensitive array based on a ratiometric calix[4]pyrrole introduced in poly(ether-urethane) hydrogel matrices with varying comonomer proportions (Anzenbacher et al., 2013). This array was used to discriminate eight different anions (acetate, benzoate, fluoride, chloride, phosphate, pyrophosphate, hydrogen sulfide, and cyanide) in urine samples and anti-inflammatory drugs with $100 \%$ classification accuracy.

Inspired by the previous works, in this study we have extended our research to the development of portable analytical system based on a fluorescent sensor array which employs familiar devices for signal acquisition (Light Emitting Diode, LED, as light source and a digital web-camera as a signal detector), in combination with chemometric methods for data treatment for fast and low-cost detection of polluting species in real samples. As sensing ligands we have used heteroatomic macrocyclic fluorophores, namely diaza-crown ethers, pyridinophans and metallocorroles, previously studied in the group, focussing a particular attention to the application of the developed analytical system to the simultaneous accurate identification of several inorganic ions which significantly influence the toxicity index of natural water, including $\mathrm{Cd}^{2+}, \mathrm{Zn}^{2+}, \mathrm{Cu}^{2+}$, and $\mathrm{NO}_{2}^{-}$. Our task was also to demonstrate the applicability of the developed analytical system for rapid visual discrimination of polluted samples, which can be adapted for in field real-time monitoring purposes.

\section{EXPERIMENTAL}

\section{Reagents}

Membrane components, namely high molecular weight poly(vinyl chloride) (PVC), tris(2-ethylhexyl) phosphate (TOP), bis(2-ethylhexyl) sebacate (DOS), Tridodecylmethylammonium chloride (TDMACl) and potassium tetrakis-(4chlorophenyl)borate (TpClPBK) were purchased from Fluka. The 2,8-dithia-5-aza-2,6-pyridinophane-based ligands bearing coumarin (HNCum) and naphthol-benzoxazole (HNBO), were newly synthesized and fully characterized at the "Dipartimento di Scienze Chimiche e Geologiche" of the University of Cagliari and at the Department of Pure and Applied Sciences of the University of Urbino, respectively (Lvova et al., 2016). The 1,10-bis[(5-phenyl-8-hydroxy-7-quinolinyl)methyl]-1,10-diaza18-crown-6-ether (DCHQ-Ph) was synthesized at the Chemistry Department "G. Ciamician" of Bologna University according to the previously reported procedure (Sargenti et al., 2017). The ligand 5-(7-methoxy coumarin-4-methyl)-2,8-dithia-5-aza-2,6pyridinophane (L3) was prepared at the "Dipartimento di Scienze Chimiche e Geologiche" of the University of Cagliari according to the method reported in (Bazzicalupi et al., 2013) and was already tested as $\mathrm{Hg}^{2+}$ selective fluorophore. The heteroatomic macrocycle [10-(4-trimhetylsilyphenyl)-5,15-dimesitylcorrole] phosphorous (V) (PCorr) was synthesized in "Tor Vergata" University according to the procedure reported in (Naitana et al., 2017). Tetrahydrofuran (THF), 4-(2-hydroxyethyl)-1piperazineethanesulfonic acid (HEPES, $\mathrm{pH}$ 7.5), $\mathrm{NaCl}, \mathrm{NaBr}$, $\mathrm{NaNO}_{2}, \mathrm{NaNO}_{3}, \mathrm{NaHCO}_{3}, \mathrm{KCl}, \mathrm{LiCl}, \mathrm{NH}_{4} \mathrm{Cl}, \mathrm{MgCl}_{2}, \mathrm{CaCl}_{2}$, $\mathrm{CoCl}_{2}, \mathrm{Zn}\left(\mathrm{NO}_{3}\right)_{2}, \mathrm{CdCl}_{2}, \mathrm{Cu}\left(\mathrm{NO}_{3}\right)_{2}$, and $\mathrm{Pb}\left(\mathrm{NO}_{3}\right)_{2}$ salts were purchased from Sigma-Aldrich. THF was freshly distilled prior to use. Ultrapure water was used for aqueous solution preparation. All the other chemicals were of analytical grade and used without any further purification.

\section{Sensors Preparation}

The membranes of about $100 \mathrm{mg}$ weight were obtained by incorporating $1 \mathrm{wt} \%$ of each fluorophore, $2-10 \mathrm{wt} \%$ of ion exchanger, TpClPBK or TDMACl in a membrane cocktail prepared with 30-33 wt $\%$ PVC and $60-66 \mathrm{wt} \%$ of plasticizer (DOS or TOP) dissolved in $1 \mathrm{~mL}$ of THF. In total 5 membranes of different compositions were prepared, Table 1. The compositions of the membranes were optimized as in our previous studies for DCHQ-Ph (Lvova et al., 2009), for HNCum and HNBO (Lvova et al., 2016), and for L3 (Bazzicalupi et al., 2013) respectively; while $\mathrm{Mb} 2$ composition was tested for the first time.

About $7 \mu \mathrm{L}$ of each membrane cocktail were cast in replicate onto the same glass slide; 10 sensing spots were deposited in total, thus providing an optical sensors array. The THF solvent was allowed to evaporate overnight to form polymeric membrane films adhesive to the glass slide surface.

\section{Sensors Testing}

All the tested membranes were photosensitive; in order to avoid photo degradation problems all of the studies were carried out on freshly prepared "disposable" optical sensors (deposited on transducer few hours prior to measurement). Membranes were kept in the dark before use. The measurements were replicated twice for each new membrane. The sensors responses toward several cations $\left(\mathrm{Na}^{+}, \mathrm{K}^{+}, \mathrm{Li}^{+}, \mathrm{NH}_{4}^{+}, \mathrm{Ca}^{2+}\right.$,

TABLE 1 | Compositions of tested polymeric membranes.

\begin{tabular}{|c|c|c|c|}
\hline Membrane & Fluorophore, wt\% & Plasticizer & TpCIPBK, wt \% \\
\hline Mb 1 & DCHQ-Ph, 1 wt\% & DOS & TpCIPBK 5 wt\% \\
\hline Mb 2 & PCorr, 0.5 wt\% & DOS & TDMACI 5 wt\% \\
\hline Mb 3 & HNCum, 1 wt\% & TOP & TpCIPBK 2 wt\% \\
\hline Mb 4 & HNBO, 1 wt\% & TOP & TpCIPBK 5 wt\% \\
\hline Mb 5 & L3, 1.3 wt\% & DOS & TpCIPBK 8 wt\% \\
\hline
\end{tabular}


$\left.\mathrm{Mg}^{2+}, \mathrm{Co}^{2+}, \mathrm{Cd}^{2+}, \mathrm{Pb}^{2+}, \mathrm{Cu}^{2+}, \mathrm{Zn}^{2+}\right)$ and anions $\left(\mathrm{Cl}^{-}, \mathrm{Br}^{-}\right.$, $\mathrm{NO}_{2}^{-}, \mathrm{NO}_{3}^{-}, \mathrm{HCO}_{3}^{-}$) potentially present in real samples, and natural waters in particular, were tested in their individual solutions with a concentration range from $3.3 \times 10^{-7}$ to 2.2 $\times 10^{-2} \mathrm{~mol} / \mathrm{L}$. The $1 \mathrm{~mol} / \mathrm{L}$ stock solutions were prepared by dissolving corresponding amounts of sodium salts for the considered anions, $\mathrm{Pb}^{2+}, \mathrm{Cu}^{2+}$, and $\mathrm{Zn}^{2+}$ nitrates, and metal chlorides for the others metal cations, in distilled water. Diluted solutions were obtained by consecutive additions of calculated amounts of the corresponding stock solution in $0.01 \mathrm{~mol} / \mathrm{L}$ HEPES ( $\mathrm{pH}$ 7.5) background solution, which was selected after a series of preliminary experiments to determine the background composition influence on the optodes response and in order to favor the $\mathrm{pH}$ conditions falling into the normal range of natural drinking water (that is 6.6-8.5).

In the second step the optical sensor array response was evaluated in multicomponent solutions containing four metal cations, namely $\mathrm{Cd}^{2+}, \mathrm{Zn}^{2+}, \mathrm{Cu}^{2+}, \mathrm{Pb}^{2+}$, and nitrite ions. In total 24 multicomponent solutions with random combinations of species concentrations (http://www.statisticshowto.com/ experimental-design/\#CompletelyRandomizedD), in the range from $1.0 \times 10^{-8} \mathrm{M}$ to $1.0 \times 10^{-4} \mathrm{M}$ were prepared. The exact composition of 24 calibration solutions is given in Table $1 \mathrm{~S}$ of Electronic Supporting Information (ESI). Two independent multivariate calibration sets, every time with a freshly deposited optode sensors were performed over a 6 month period. For each ion a working concentration interval was determined according to its level of toxicity based on the World Health Organization guidelines (World Health Organization, 2017). Since $\mathrm{Cd}^{2+}$ is the most toxic species, five different concentrations were tested for it, while we have limited the remaining species to three concentrations, Table 2. The sample solutions contained four different heavy metal ions: $\mathrm{Cd}^{2+}, \mathrm{Zn}^{2+}, \mathrm{Pb}^{2+}$, and $\mathrm{Cu}^{2+}$ having randomly combined concentrations. Each new calibration solution was prepared directly prior to measurement in the measurement cuvette; for this, $3 \mathrm{~mL}$ of $0.01 \mathrm{~mol} / \mathrm{L}$ HEPES $\mathrm{pH} 7.5$ background buffer were placed in a cuvette, and the calculated amounts of $\mathrm{CdCl}_{2}, \mathrm{Cu}\left(\mathrm{NO}_{3}\right)_{2}, \mathrm{Zn}\left(\mathrm{NO}_{3}\right)_{2}, \mathrm{~Pb}\left(\mathrm{NO}_{3}\right)_{2}$, and $\mathrm{NaNO}_{2}$ stock solutions of known concentrations (1.0 $\times 10^{-6}, 1.0 \times 10^{-4}$, and $\left.1.0 \times 10^{-2} \mathrm{~mol} / \mathrm{L}\right)$ were added subsequently and stirred to obtain a homogenous solution. Sensor array was conditioned in multicomponent calibration solution for about $4 \mathrm{~min}$ prior the measurement, in order to allow fluorophore-analyte interaction.

Optical response of the array was measured with a photometric setup, performed in polystyrene cuvettes of $10 \mathrm{~mm}$ path length using a Photoassisted Technique (PT) setup (Lvova et al., 2017) in which a blue-colored InGaN LED (Roithner LaserTechnik, Austria, model H2A1-H385, $\lambda_{\text {ex }}=380 \mathrm{~nm}$ ) was employed as monochromic external light source. A frontally placed digital camera (Philips SPC900NC for notebook with a resolution of $352 \times 288$ pixels) was used as a signal detector. The transparent cuvette was laterally illuminated with LED and the responses of the sensor array upon analyte addition were recorded from tree channels representing main visible spectrum colors: red $(630 \mathrm{~nm})$, green $(530 \mathrm{~nm})$, and blue $(480 \mathrm{~nm})$. Additionally, for
TABLE 2 | Composition of multicomponent solutions and corresponding WHO guideline values.

\begin{tabular}{|c|c|c|}
\hline Ion & $\begin{array}{l}\text { WHO guideline value, } \\
\text { mg/L }\end{array}$ & Concentrations, mol/L \\
\hline $\mathrm{Cd}^{2+}$ & $0.003\left(2.6 \times 10^{-8} \mathrm{~mol} / \mathrm{L}\right)$ & $\begin{array}{c}1.0 \times 10^{-8} ; 3.3 \times 10^{-7} ; 1.6 \times 10^{-6} ; 3.3 \\
\times 10^{-5} ; 1.0 \times 10^{-4}\end{array}$ \\
\hline $\mathrm{Pb}^{2+}$ & $0.01\left(4.8 \times 10^{-8} \mathrm{~mol} / \mathrm{L}\right)$ & $1.0 \times 10^{-8} ; 8.3 \times 10^{-7} ; 3.3 \times 10^{-5}$ \\
\hline $\mathrm{Cu}^{2+}$ & $2\left(3.1 \times 10^{-5} \mathrm{~mol} / \mathrm{L}\right)$ & $3.3 \times 10^{-5} ; 6.6 \times 10^{-5} ; 1.0 \times 10^{-4}$ \\
\hline $\mathrm{NO}_{2}^{-}$ & $3\left(6.5 \times 10^{-5} \mathrm{~mol} / \mathrm{L}\right)$ & $1.6 \times 10^{-6} ; 3.3 \times 10^{-5} ; 1.0 \times 10^{-4}$ \\
\hline $\mathrm{Zn}^{2+}$ & $3\left(4.6 \times 10^{-5} \mathrm{~mol} / \mathrm{L}\right)^{\star}$ & $1.6 \times 10^{-6} ; 3.3 \times 10^{-5} ; 1.0 \times 10^{-4}$ \\
\hline
\end{tabular}

For the full composition of calibration solutions see Table $1 S$ in the Electronic Supplementary Information (ESI). *A guideline value for $\mathrm{Zn}^{2+}$ is not established since it is not of health concern at levels found in drinking-water; however, drinking-water containing zinc at levels above $3 \mathrm{mg} / \mathrm{l}$ may not be acceptable to consumers due to the undesirable astringent taste and formation of a greasy film when boiled.

each sensing spot the luminescence intensity was calculated according to:

$$
\mathrm{I}=(\mathrm{R}+\mathrm{G}+\mathrm{B}) /(3 \times 255)
$$

where $R, G$, and $B$ represent the sensing spot luminescence intensities at RGB channels, and value 255 represents the maximum intensity of optical signal measured with webcam detector. The RGB signal was evaluated after background luminosity subtraction. The duration of the overall sample illumination was $50 \mathrm{~s}$, during this period 10 photographic shoots were taken every $5 \mathrm{~s}$, and the final optical signal was a mean value of the records. The measurement cell was properly shielded from ambient illumination. The responses of the membranes were registered and transformed in analytically useful digital signal by in house written MATLAB (v.7.0, 2005, The MathWorks, Inc., Natick, USA) codes.

\section{Real Samples}

The applicability of the proposed indirect method in single sensor mode was evaluated by assaying the amount of $\mathrm{Cd}^{2+}$ and $\mathrm{NO}_{2}^{-}$ ions spiked in five natural water samples: three were taken from the Rome city famous Fountains, such as Fontana di Trevi, Fontana dei Quattro Fiumi in Piazza Navona and the Fontana del Nettuno in Piazza del Popolo, one was sampled at the surface of the Tiber river that crosses the city of Rome (Isola Tiberina zone, Rome, Italy) and the other sample was a marine water sampled in the public beach area of Torvajanica, $20 \mathrm{~km}$ far from Rome city center (Lazio region, Italy). The standard addition method was employed, for this the additions of $1.0 \times 10^{-8} \mathrm{~mol} / \mathrm{L}$ and $1.7 \times$ $10^{-7} \mathrm{~mol} / \mathrm{L}$ of $\mathrm{Cd}^{2+}$ ions or $3.2 \times 10^{-5} \mathrm{~mol} / \mathrm{L}$ and $9.6 \times 10^{-5}$ $\mathrm{mol} / \mathrm{L}$ for $\mathrm{NO}_{2}^{-}$ions respectively were performed to $3 \mathrm{~mL}$ of $1: 1$ mixture of water sample with 0.01M HEPES buffer at $\mathrm{pH}$ 7.5. The luminescence variance of the sensor array was registered with the PT technique.

\section{Multivariate Data Analysis}

The chemometric approach was employed to treat data obtained from the optical multisensor array. The Principal Component 
Analysis (PCA) and Partial Least Squares (PLS) regression method were applied to interpret the optical output of the sensor array based on membranes $\mathrm{Mb1-Mb5}$ and employed for analysis of the $\mathrm{Cd}^{2+}$ and $\mathrm{NO}_{2}^{-}$content in natural water samples. PLS1 was used to correlate the optode array output (Y-variable) with the known concentrations of $\mathrm{Cd}^{2+}, \mathrm{Zn}^{2+}, \mathrm{Cu}^{2+}$, and $\mathrm{NO}_{2}^{-}$ions in 24 multicomponent solutions (X-variables, see Table 2). Data treatment was performed with commercial Unscrambler (v. 9.1, 2004, CAMO PROCESS AS, Norway). Due to the restricted number of analyzed samples the validation was performed by using a leave-one-out cross-validation procedure. The RMSEC and RMSEV (Root Mean Square Error of Calibration and Validation, correspondingly) and the correlation coefficients, $R^{2}$, of predicted versus measured correlation lines were used to evaluate the efficiency of the applied regression model.

\section{RESULTS AND DISCUSSION}

\section{Selection of Fluorophores and Fluorescent Sensor Array Construction}

The chemical structures of studied fluorescent ligands are shown in Figure 1. All these compounds have been chosen thanks to their particular emission properties when interacting with metal cations.
The main criteria for the chemosensors selection were as following: (i) the presence in their structure of a macrocyclic chelating site which is linked to (or functions as) an the optically active fluorogenic fragment modulating (enhancing or quenching) the fluorescence emission upon the analyte binding; (ii) strong absorption around $350-450 \mathrm{~nm}$ in the near-UV region and high luminescence in the visible diapason; (iii) cross-sensitive properties, i.e., a strong binding ability toward several analytes; (iv) the availability in commerce or simple synthetic procedures required for their synthesis. The selected chemosensors bear in their structure different kinds of binding receptor units (pyridinophane in HNCum, HNBO and L3; diaza-crown ether in DCHQ-Ph and corrole macrocycle in PCorr), while coumarine, quinoline and naphtholbenzoxazole serve as fluorogenic signaling fragments. Due to the different coordination properties, these compounds have different signal transduction schemes, such as fluorescence quenching or enhancement, which may vary from one analyte to another thus permitting to obtain enough information to allow to discriminate various analytes with a small number of sensing ligands. Among selected compounds, DCHQ-Ph was tested recently by our group as selective fluorophore for $\mathrm{Mg}^{2+}$ detection (Lvova et al., 2017). In non-complexed DCHQ-Ph, hydroxyquinoline signaling unit is poorly luminescent due to an intermolecular photoinduced proton transfer (PPT) process between the hydroxyl group<smiles>OCCOCCN(CCOCCOCCN1CCOCCOCCN(Cc2c(O)c(-c3ccccc3)c(O)c3ncccc23)CC1)Cc1cc(-c2ccccc2)c2cccnc2c1O</smiles>

DCHQ-Ph

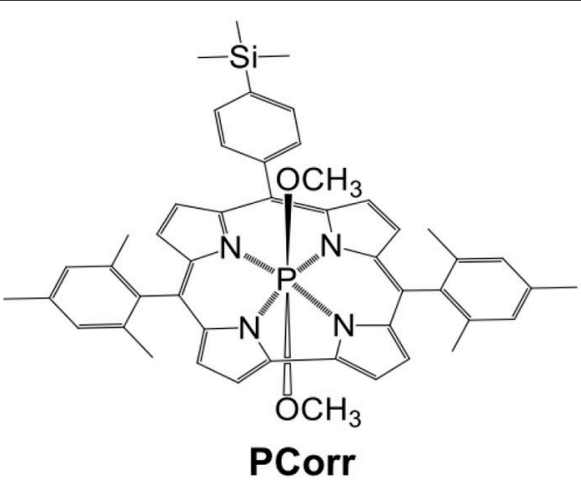

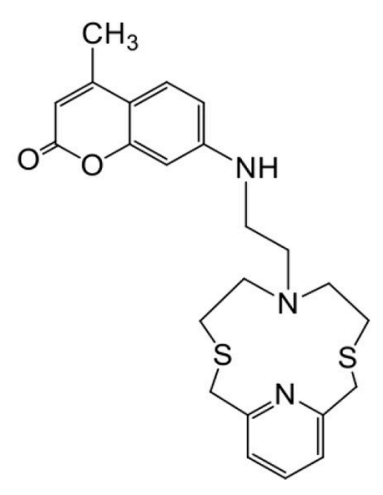

HNCum

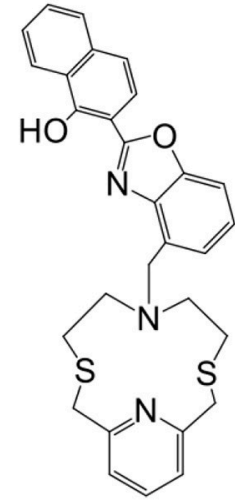

HNBO

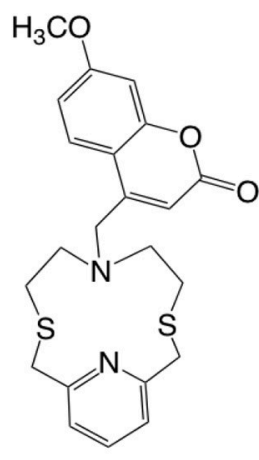

L3

FIGURE 1 | Molecular structures of the fluorescent ligands used inside solvent polymeric membranes optical sensor array. 


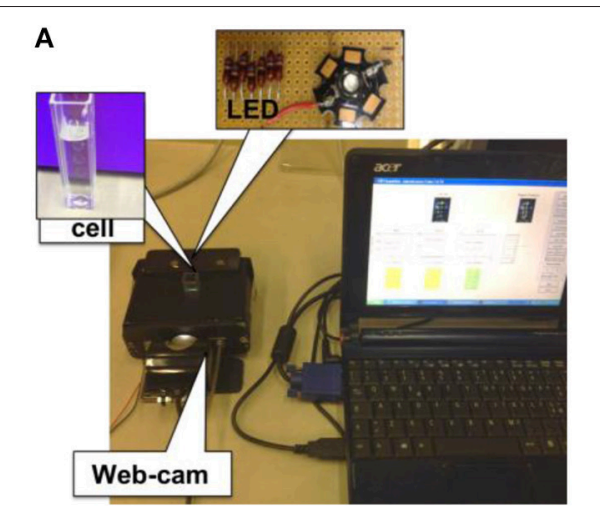

B

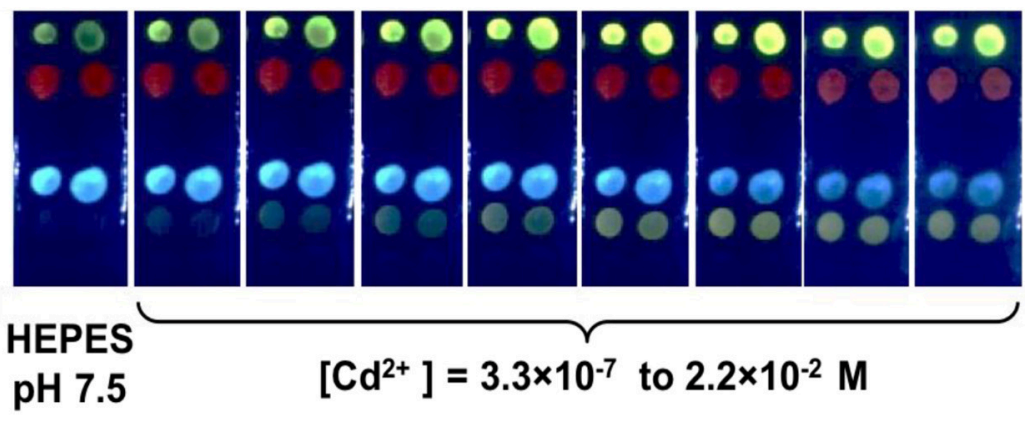

FIGURE 2 | (A) The employed PT measurement setup; (B) the photogram of PT response of optical sensor array toward individual solutions of $\mathrm{CdCl}_{2}$ salt in the concentration range from $3.3 \times 10^{-7}$ to $2.2 \times 10^{-2} \mathrm{~mol} / \mathrm{L}$.

and the quinoline nitrogen, while a significant fluorescence enhancement is observed in the DCHQ-Ph- $\mathrm{Mg}^{2+}$ complex where both groups are involved in metal coordination and PPT is inhibited. The compound L3 was reported previously in the literature and its luminescence properties in the presence of different cations was studied (Bazzicalupi et al., 2013). As a free ligand, the coumarin signaling unit of L3 is partially quenched, and upon the coordination to metal cations a chelation enhanced fluorescence emission (CHEF effect) is observed. The HNCum and $\mathrm{HNBO}$ fluorophores were tested previously as selective ligands for $\mathrm{Cd}^{2+}$ and $\mathrm{Zn}^{2+}$ detection (Lvova et al., 2016). For these compounds the involvement of a large part of donor atoms of the macrocyclic receptor unit and the fluorogenic signaling unit was observed in complexation, with a photoinduced electron transfer process (PET) determining the fluorescence intensity emission change. Moreover, emission wavelength shift upon cations complexation by HNBO indicates also the contribution of an intramolecular charge transfer process (ICT) to the ligand fluorescence response. Finally, the optical properties of PCorr as anion-sensitive ligand were studied in the present work for the first time, however the physico-chemical properties (Naitana et al., 2017) and possible sensing mechanism of similar compounds have been previously discussed in the literature (Lvova et al., 2009).

As mentioned above, all the selected chemosensors exhibit a strong absorbance in the range from 350 to $450 \mathrm{~nm}$, which permitted us to employ the single monochromic light source for sensor array excitation. A commercially available blue-colored Light Emitting Diode (LED, $\lambda_{\text {ex }}=380 \mathrm{~nm}$ ) with home-made hardware was employed as an external monochromatic light source. Figure $\mathbf{2 A}$ shows a picture of the employed measurement setup and the arrangement of its major components: measurement cell with a sensor array placed inside, LED, web-camera and measurement chamber, where the sensitive substrate is placed. In this setup the webcam registers the luminescence variation of sensing spots upon the backside illumination with LED in the absence and in the presence of the analytes. In Figure 2B the typical PT response of the sensor array is shown during the calibration in individual solutions of
$\mathrm{CdCl}_{2}$ salt in concentration range from $3.3 \times 10^{-7}$ to $2.2 \times 10^{-2}$ $\mathrm{mol} / \mathrm{L}$. The significant changes in the luminescence emission were recorded for the membranes Mb1, Mb3, and Mb4 based on DCHQ-Ph, HNCum and HNBO respectively.

In the same way, the response of optical sensor arrays based on Mb1-Mb5 was tested in individual solutions of 11 cations and 5 anions in $0.01 \mathrm{~mol} / \mathrm{L}$ HEPES buffer at $\mathrm{pH}$ 7.5 and $\lambda_{\mathrm{ex}}=380 \mathrm{~nm}$ LED illumination, and it was found that most of tested heavy metal ions resulted in analytespecific luminescence changes of singular sensors; while PCorrbased Mb2 was particularly sensitive to changes in nitriteions concentration demonstrating the luminescence quenching upon the analyte concentration growth. Figure $\mathbf{3 A}$ shows several examples of Mb1-Mb5 PT-responses toward analytes with the highest registered luminescence change. In fact, the inspection of sensing spot emission patterns indicated that $\mathrm{Mb} 1$ and $\mathrm{Mb} 3$ were most sensitive to $\mathrm{Cd}^{2+}$ and $\mathrm{Cu}^{2+}, \mathrm{Mb} 4$ to $\mathrm{Cd}^{2+}$ and $\mathrm{Zn}^{2+}$, while $\mathrm{Mb} 5$ and $\mathrm{Mb} 2$ to ammonium and nitrite ions, respectively. Figure 3B shows the comparison of fluorescence responses of membranes $\mathrm{Mb} 1-\mathrm{Mb} 5$ represented as the difference of luminescence intensities evaluated according to Equation (1) for all the tested analytes in concentration $2.9 \times 10^{-4} \mathrm{~mol} / \mathrm{L}$ into $0.01 \mathrm{~mol} / \mathrm{L}$ HEPES buffer background at $\mathrm{pH}$ 7.5. The differences in Mb1-Mb5 responses clearly indicate the crosssensitive response of these sensing materials to several heavy metal ions, $\mathrm{Cd}^{2+}, \mathrm{Zn}^{2+}, \mathrm{Cu}^{2+}$, and nitrite-anion in particular.

According to WHO recommendations, these species are responsible for organoleptic faults $\left(\mathrm{Zn}^{2+}\right.$ ions) and health risks $\left(\mathrm{Cd}^{2+}, \mathrm{Cu}^{2+}\right.$, and $\left.\mathrm{NO}_{2}^{-}\right)$while found in environment, and in natural waters in particular (World Health Organization, 2017). As a consequence, we have decided to employ the sensor array based on Mb1-Mb5 for rapid screening of multicomponent contamination of real samples with these analytes.

\section{Multivariate Calibration of Optical Sensor Array}

The optical response of sensor array based on Mb1-Mb5 was evaluated in 24 calibration solutions containing various concentrations of $\mathrm{Cd}^{2+}, \mathrm{Zn}^{2+}, \mathrm{Cu}^{2+}, \mathrm{Pb}^{2+}$, and $\mathrm{NO}_{2}^{-}$ions. 

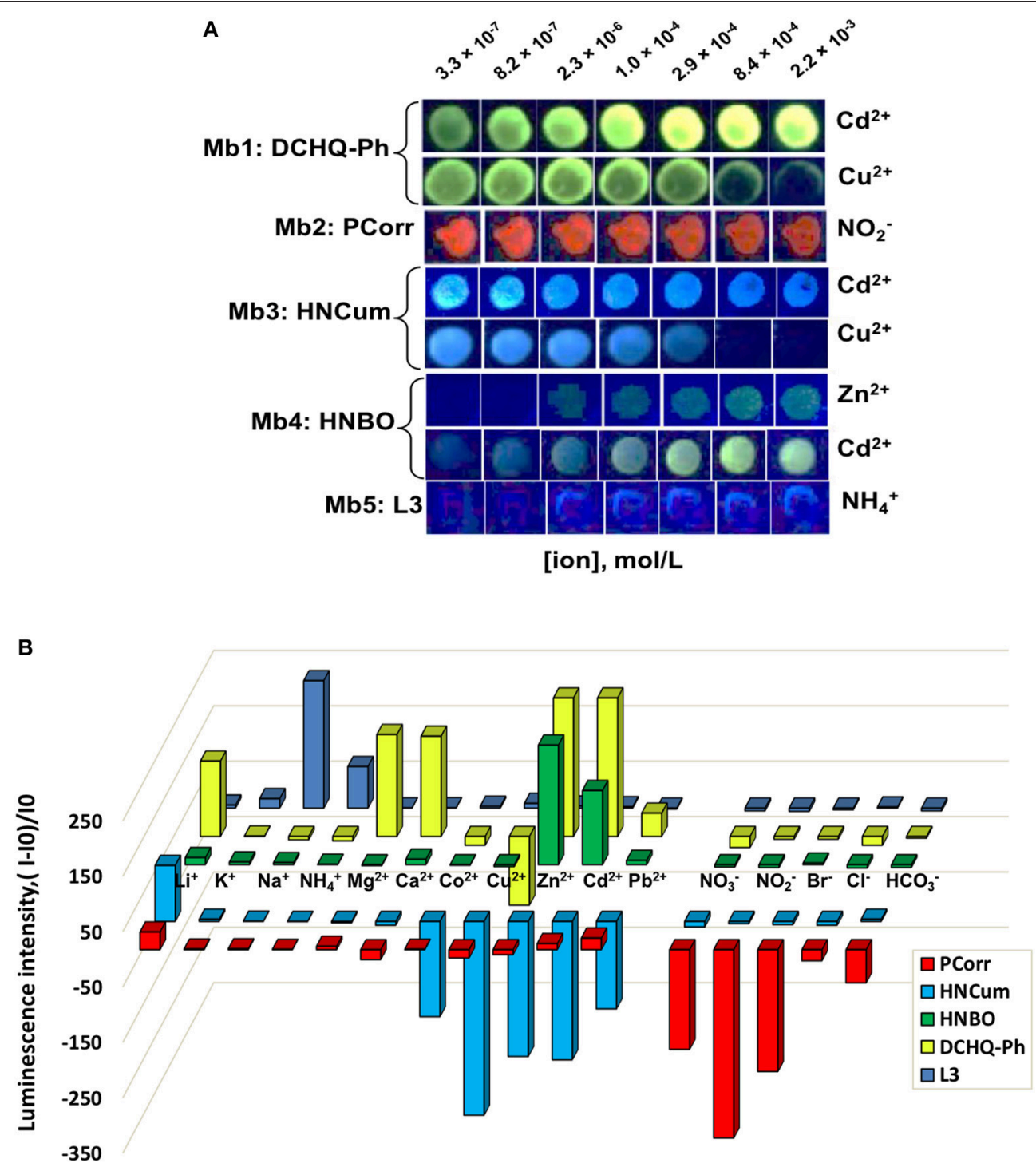

FIGURE 3 | Fluorescence responses of membranes Mb1-Mb5 toward several analytes in their individual solutions evaluated with PT at $\lambda$ ex $=380$ nm LED illumination in $0.01 \mathrm{~mol} / \mathrm{L}$ HEPES buffer at $\mathrm{pH}$ 7.5. (A) Photograms of sensors PT responses with the highest registered luminescence changes; (B) pattern of the relative intensity changes of membranes Mb1-Mb5 toward all tested analytes at a concentration of $2.9 \times 10^{-4} \mathrm{~mol} / \mathrm{L}$.

The full composition of calibration solutions is given in Table $1 \mathrm{~S}$ of ESI, while the range of concentrations of five ions is given in Table 2. To prepare these multicomponent solutions we considered the guidelines for these ionic species in potable water established by WHO (World Health Organization, 2017), which correspond to $0.003 \mathrm{mg} / \mathrm{L}$ for $\mathrm{Cd}^{2+}, 0.01 \mathrm{mg} / \mathrm{L}$ for $\mathrm{Pb}^{2+}$, $2 \mathrm{mg} / \mathrm{L}$ for $\mathrm{Cu}^{2+}$, and $3 \mathrm{mg} / \mathrm{L}$ for $\mathrm{NO}_{2}^{-}$, respectively. No healthbased WHO guideline value for $\mathrm{Zn}^{2+}$ is provided, but the drinking water containing $\mathrm{Zn}^{2+}$ at concentrations above $3 \mathrm{mg} / \mathrm{L}$ $\left(4.6 \times 10^{-5} \mathrm{~mol} / \mathrm{L}\right)$ has an undesirable astringent taste, may appear opalescent and develops a greasy film when boiled (World Health Organization, 2017). Hence, in our tests we have used concentration values for $\mathrm{Zn}^{2+}$ lower than $3 \mathrm{mg} / \mathrm{L}$. For each ion a working concentration interval was defined according to its level of toxicity. Since $\mathrm{Cd}^{2+}$ is the most toxic specie among the tested analytes, four different concentration levels were tested for it, while the concentrations of $\mathrm{Zn}^{2+}, \mathrm{Pb}^{2+}, \mathrm{NO}_{2}^{-}$, and $\mathrm{Cu}^{2+}$ ions were limited to three levels. The photogram of sensor array PT response in all 24 multicomponent solutions is shown in Figure 4. The clear difference in $\mathrm{Mb} 1-\mathrm{Mb} 5$ responses can be observed, with especially strong emission in solutions where $\mathrm{Cd}^{2+}$ and $\mathrm{Zn}^{2+}$ ions are present in high concentrations.

Application of PCA analysis to the numerical outputs of sensor array luminescence response in terms of RGB intensities has permitted to identify clearly two groups of solutions corresponding to control solutions without pollutants addition (0.01 $\mathrm{ml} / \mathrm{L}$ HEPES, $\mathrm{pH}$ 7.5) and all the multicomponent calibration solutions respectively, Figure 5. Moreover, the real 

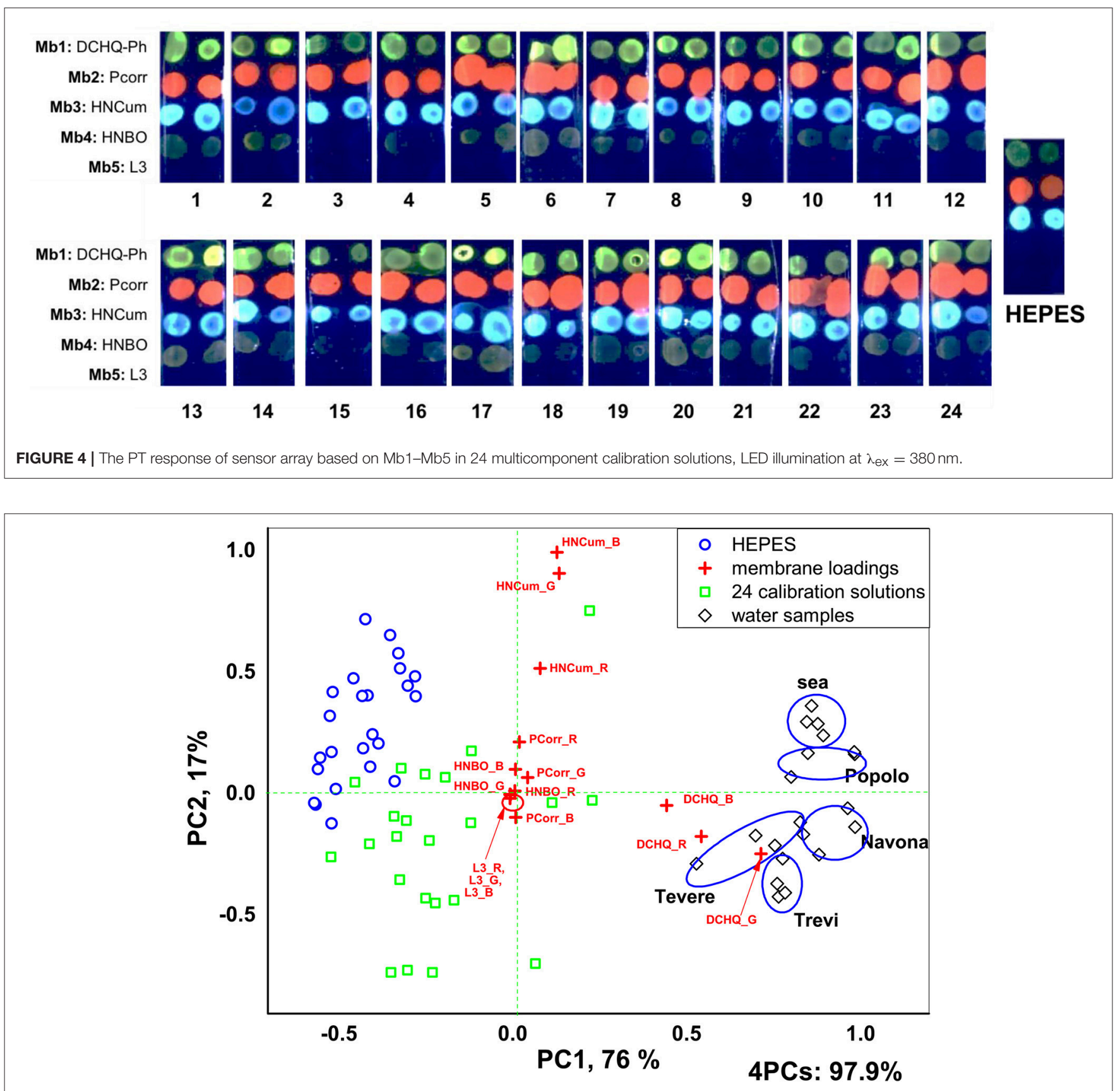

FIGURE 5 | PCA scores and loadings plot of the Mb1-Mb5 sensor array fluorescence responses in 24 multicomponent calibration solutions.

water samples were clearly distinguished from calibration solutions and between each other. $97.9 \%$ of the total variance was explained for 4 PCs and the highest influence (highest loadings) on solutions discrimination was shown by the $\mathrm{Mb} 1$ and Mb3 based on DCHQ-Ph and HNCum ligands, respectively.

Furthermore, PLS1 regression models were calculated for all the polluting species employing Mb1-Mb5 sensing spots luminescence intensity calculated according to the Equation (1); the luminescence intensities were obtained by subtraction of background luminescence intensity (the luminescence intensity of glass slide without sensing layer) and sensing spots luminescence intensity in $0.01 \mathrm{~mol} / \mathrm{L}$ HEPES $\mathrm{pH} 7.5$ without analytes. The linear correlations in all the range of tested concentrations with the following $R^{2}$ coefficient, number of PCs representing the highest system variance, RMSEC and RMSECV values were found for $\mathrm{Cd}^{2+}\left(R^{2}=0.893\right.$, PCs $=4$, $\mathrm{RMSEC}=0.47 \mathrm{pCd}, \mathrm{RMSEV}=0.64 \mathrm{pCd})$, for $\mathrm{Cu}^{2+}\left(R^{2}=0.906\right.$, 
PCs $=3$, RMSEC $=0.057 \mathrm{pCu}$, RMSEV $=0.064 \mathrm{pCu})$, for $\mathrm{Zn}^{2+}\left(R^{2}=0.912\right.$, PCs $=3$, RMSEC $=0.216 \mathrm{pZn}$, $\mathrm{RMSEV}=0.315 \mathrm{pZn})$ and for $\mathrm{NO}_{2}^{-}\left(R^{2}=0.925, \mathrm{PCs}=3\right.$, RMSEC $=0.199 \mathrm{pNO}_{2}, \mathrm{RMSEV}=0.302 \mathrm{pNO}_{2}$,), respectively, Figure 1S. The detection limits (DL) for two polluting species of interest, $\mathrm{Cd}^{2+}$ and $\mathrm{NO}_{2}^{-}$ions were estimated by $3 \sigma$ method $(\mathrm{DL}=3 \sigma / \mathrm{S}$, where $\sigma$ is the RMSEC recalculated in $\mathrm{mol} / \mathrm{L}$ and $S$ is the slope of the regression line at calibration stage). DL for $\mathrm{Cd}^{2+}$ was $0.0013 \mathrm{mg} / \mathrm{L}$ and for $\mathrm{NO}_{2}^{-}$was $0.21 \mathrm{mg} / \mathrm{L}$. Such a result is promising, considering that the obtained DL value for $\mathrm{Cd}^{2+}$ and $\mathrm{NO}_{2}^{-}$were lower than the WHO provisional guideline values of 0.003 and $2 \mathrm{mg} / \mathrm{L}$, respectively.

\section{Real Samples Analysis}

We then have evaluated the added amounts of $\mathrm{Cd}^{2+}$ and $\mathrm{NO}_{2}^{-}$ions in five natural water samples: tree samples taken from the Rome city fountains, one sample of surface water from the Tiber river and marine water sample. Since the concentrations of these two polluting species are usually low, we evaluated the real sample by introducing ions to water samples in two concentrations, one corresponding to $\mathrm{WHO}$ guideline value for potable water and another in several times higher of WHO limit. These concentrations were $1.0 \times 10^{-8}$ $\mathrm{mol} / \mathrm{L}$ and $1.7 \times 10^{-7} \mathrm{~mol} / \mathrm{L}$ for $\mathrm{Cd}^{2+}$, and were $3.2 \times$ $10^{-5} \mathrm{~mol} / \mathrm{L}$ and $9.6 \times 10^{-5} \mathrm{~mol} / \mathrm{L}$ for $\mathrm{NO}_{2}^{-}$, respectively. The luminescence variance of sensors array before and after pollutants addition was registered with PT technique and the previously calculated PLS1 regression models were used to evaluate the added pollutant amounts. The measurements were repeated twice for two disposable sensor arrays, $n=4$. The obtained recoveries were in the range from 90.5 to $106.6 \%$ for $\mathrm{Cd}^{2+}$ and in the range from 95.1 to $105.1 \%$ for $\mathrm{NO}_{2}^{-}$with the mean RSD of $3.7 \%\left(\mathrm{Cd}^{2+}\right)$ and $2.61 \%\left(\mathrm{NO}_{2}^{-}\right)$respectively. Due to the high salinity the detection of $\mathrm{NO}_{2}^{-}$ions in sea water was not possible, while satisfactory results for $\mathrm{Cd}^{2+}$ ions analysis in this sample were obtained (see Table $2 S$ in the ESI).

\section{REFERENCES}

Abbasi-Moayed, S., Golmohammadi, H., and Hormozi-Nezhad, M. R. (2018). A nanopaper-based artificial tongue: a ratiometric fluorescent sensor array on bacterial nanocellulose for chemical discrimination applications. Nanoscale 10, 2492-2502. doi: 10.1039/C7NR05801B

Amatori, S., Ambrosi, G., Fanelli, M., Formica, V., Fusi, V., Giorgi, L., et al. (2012). Multi-use NBD-based tetra-amino macrocycle: fluorescent probe for metals and anions and live cell marker. Chem. Eur. J. 18, 4274-4284. doi: 10.1002/chem.201103135

Ambrosi, G., Borgogelli, E., Formica, M., Fusi, V., Giorgi, L., Micheloni, M., et al. (2015). PluS Nanoparticles as a tool to control the metal complex stoichiometry of a new thio-aza macrocyclic chemosensor for $\mathrm{Ag}(\mathrm{I})$ and $\mathrm{Hg}(\mathrm{II})$ in water. Sens. Actu. B 207, 1035-1044. doi: 10.1016/j.snb.2014.07.107

Anzenbacher, P. Jr., Liu, Y., Palacios, M. A., Minami, T., Wang, Z., and Nishiyabu, R. (2013). Leveraging material properties in fluorescence anion sensor arrays: a general approach. Chem. Eur. J. 19, 8497-8506. doi: 10.1002/chem.201204188

\section{CONCLUSIONS}

In this paper we have reported an optical sensor array based on heteroatomic macrocyclic fluorophores (diaza-crown ether, metallocorrole and pyridinophans) for the photographic analysis of liquid media. The results obtained indicate a potential utility of the developed optical system for the accurate monitoring of polluting species, namely cadmium and nitrite ions, in real samples. The combination with familiar devices and the use of the PT measurement technique can allow inexpensive, rapid and accurate monitoring of heavy metals and anions pollution of natural environments that can be performed by untrained personnel.

\section{AUTHOR CONTRIBUTIONS}

All authors listed have made a substantial, direct and intellectual contribution to the work, and approved it for publication.

\section{FUNDING}

Fondazione di Sardegna, Regione autonoma della Sardegna, University of Urbino.

\section{ACKNOWLEDGMENTS}

VL and AG thank Fondazione di Sardegna (FdS) and Regione autonoma della Sardegna (RAS) (Progetti Biennali di Ateneo FdS/RAS annualità 2016) for financial support. LG and VF acknowledge the Department of Pure and Applied Sciences, University of Urbino, (DiSPeA_Fusi_prog17) for financial support.

\section{SUPPLEMENTARY MATERIAL}

The Supplementary Material for this article can be found online at: https://www.frontiersin.org/articles/10.3389/fchem. 2018.00258/full\#supplementary-material

Arca, M., Caltagirone, C., De Filippo, G., Formica, M., Fusi, V., Giorgi, L., et al. (2014). A fluorescent ratiometric nanosized system for the determination of Pd(II) in water. Chem. Comm. 50, 15259-15262. doi: 10.1039/C4CC07969H

Askim, J. R., Mahmoudi, M., and Suslick, K. S. (2013). Optical sensor arrays for chemical sensing: the optoelectronic nose. Chem. Soc. Rev. 42, 8649-8682. doi: $10.1039 /$ c3cs60179j

Bazzicalupi, C., Caltagirone, C., Cao, Z., Chen, Q., Di Natale, C., Garau, A., et al. (2013). Multimodal use of new coumarin-based fluorescent chemosensors: towards highly selective optical sensors for $\mathrm{Hg}^{2+}$ probing. Chem. Eur. J. 19, 14639-14653. doi: 10.1002/chem.201302090

Bolse, N., Eckstein, R., Schend, M., Habermehl, A., Eschenbaum, C., HernandezSosa, G., et al. (2017). A digitally printed optoelectronic nose for the selective trace detection of nitroaromatic explosive vapours using fluorescence quenching. Flex. Printed Electron. 2:024001. doi: 10.1088/2058-8585/aa6601

Bonifazi, G., and Serranti, S. (2016). Chemical imaging: an innovative tool for particulate matter characterization and sorting. Particul. Sci. Technol. 34, 470-482. doi: 10.1080/02726351.2015.1115453 
Di Natale, C., Dini, F., and Scozzari, A. (2016). Non-conventional electrochemical and optical sensor systems. Handb. Environ. Chem. 40, 279-311. doi: 10.1007/698_2013_254

Grigg, J. (2004). Environmental toxins: their impact on children's health. Arch. Dis. Child. 89, 244-250. doi: 10.1136/adc.2002.022202

Guanais Goncalves, C., Dini, F., Martinelli, E., Catini, A., Lundström, I., Paolesse, R., et al. (2016). Detection of diverse potential threats in water with an array of optical sensors. Sens. Act. B 236, 997-1004. doi: 10.1016/j.snb.2016.04.080

Han, J., Bender, M.,Seehafer, K., and Bunz, U. H. F. (2016). Identification of white wines by using two oppositely charged poly(p-phenyleneethynylene)s individually and in Complex. Ang. Chem. Int. Ed. 55, 7689-7692. doi: 10.1002/anie.201602385

Jing, W., Lu, Y., Yang, G., Wang, F., He, L., and Liu, Y. (2017). Fluorescence sensor array based on amino acids-modulating quantum dots for the discrimination of metal ions. Anal. Chim. Acta 985, 175-182. doi: 10.1016/j.aca.2017.07.011

Kang, H., Lin, L., Rong, M., and Chen, X. (2014). A cross-reactive sensor array for the fluorescence qualitative analysis of heavy metal ions. Talanta 129, 296-302. doi: 10.1016/j.talanta.2014.05.054

Lee, J. Y., Friedman, J. E., Angel, I., Kozak, A., and Koh, J. Y. (2004). The lipophilic metal chelator DP-109 reduces amyloid pathology in brains of human betaamyloid precursor protein transgenic mice. Neurobiol. Aging 25, 1315-1321. doi: 10.1016/j.neurobiolaging.2004.01.005

Lei, J., Hou, C., Huo, D., Luo, X., Li, Y., Fa, H., et al. (2016). A novel detector using a fluorescent sensor array and discrimination of pesticides. Res. Chem. Intermed. 42, 7359-7374. doi: 10.1007/s11164-016-2541-8

Lin, Q., Lu, T.- T., Zhu, X., Sun, B., Yang, Q.- P., Wei, T.-B., et al. (2015). A novel supramolecular metallogel-based high-resolution anion sensor array. Chem. Commun. 51, 1635-1638. doi: 10.1039/C4CC07814D

Liu, F., Ha, H. D., Han, D. J., and Seo, T. S. (2013). Photoluminescent graphene oxide microarray for multiplex heavy metal ion analysis Small 9, 3410-3414. doi: 10.1002/smll.201300499

Liu, Y., Mettry, M., Gill, A. D., Perez, L., Zhong, W., and Hooley, R. J. (2017). Selective heavy element sensing with a simple host-guest fluorescent array. Anal. Chem. 89, 11113-11121. doi: 10.1021/acs.analchem.7b03377

Lu, Y. (2014). Optical chemical sensor array based on functional nanomaterials. Prog. Chem. 26, 931-938. doi: 10.7536/PC131236

Lvova, L., Di Natale, C., D’Amico, A., and Paolesse, R. (2009). Corrolebased ion-selective electrodes. J. Porphyrins Phthalocyan. 13, 1168-1178. doi: 10.1142/S1088424609001510

Lvova, L., Di Natale, C., Paolesse, R., Giorgi, L., Fusi, V., Garau, A., et al. (2016). Photographic detection of cadmium(II) and zinc(II) ions. Proc. Eng. 168, 346-350. doi: 10.1016/j.proeng.2016.11.117

Lvova, L., Galloni, P., Floris, B., Lundström, I., Paolesse, R., and Di Natale, C. (2013). A ferrocene-porphyrin ligand for multi-transduction chemical sensor development. Sensors 13, 5841-5856. doi: 10.3390/s130505841

Lvova, L., Guanais Gonçalves, C., Prodi, L., Lombardo, M., Zaccheroni, N., Viaggiu, E., et al. (2018). Non-enzymatic portable optical sensor for Microcystin-LR. Chem. Commun. 54, 2747-2750. doi: 10.1039/C7CC09830H

Lvova, L., Guanais Gonçalves, C., Prodi, L., Sgarzi, M., Zaccheroni, N., Lombardo, M., et al. (2017). Systematic approach in $\mathrm{Mg}^{2+}$ ions analysis with a combination of tailored fluorophore design. Anal. Chim. Acta 988, 96-103. doi: 10.1016/j.aca.2017.07.062

Lvova, L., Kirsanov, D., Legin, A., and Di Natale, C., (eds.). (2014). Multisensor Systems for Chemical Analysis - Materials and Sensors. Singapore: Pan Stanford Publishing.

Lvova, L., Pudi, R., Galloni, P., Lippolis, V., Di Natale, C., Lundstrom, I., et al. (2015). Multi-transduction sensing films for Electronic Tongue applications. Sens. Act B 207B, 1076-1086. doi: 10.1016/j.snb.2014.10.086

Moczko, E., Mirkes, E. M., Cáceres, C., Gorban, A. N., and Piletsky, S. (2016). Fluorescence-based assay as a new screening tool for toxic chemicals. Sci. Rep. 6:33922. doi: 10.1038/srep33922

Mungkarndee, R., Techakriengkrai, I., Tumcharern, G., and Sukwattanasinitt, M. M. (2016). Fluorescence sensor array for identification of commercial milk samples according to their thermal treatments. Food Chem. 197, 198-204. doi: 10.1016/j.foodchem.2015.10.083
Mungkarndee, R., Tumcharern, G., Thiramanus, R., Techakriengkrai, I., and Sukwattanasinitt, M. (2015). Fluorescence sensor arrays for identification of foodborne pathogens. Anal. Methods 7, 7431-7435. doi: 10.1039/C5AY0 $0797 \mathrm{~F}$

Naitana, M. L., Nardis, S., Pomarico, G., Raggio, M., Caroleo, F., Cicero, D. O., et al. (2017). A highly emissive water-soluble phosphorus corrole. Chem. Eur. J. 23, 905-916. doi: 10.1002/chem.201604233

Nishi, K., Isobe, S.-I., Zhu, Y., Kiyama, R. (2015). Fluorescence-based bioassays for the detection and evaluation of food materials. Sensors 15, 25831-25867. doi: $10.3390 / \mathrm{s} 151025831$

Niu, L.-Y., Li, H., Feng, L., Guan, Y.- S., Chen, Y.- Z., Duan, C.- F., et al. (2013). BODIPY-based fluorometric sensor array for the highly sensitive identification of heavy-metal ions. Anal. Chim. Acta 775, 93-99. doi: 10.1016/j.aca.2013.03.013

Peng, J., Li, J., Xu, W., Wang, L., Su, D., Teoh, C. L., et al. (2018). Silica nanoparticle-enhanced fluorescent sensor array for heavy metal ions detection in colloid solution. Anal. Chem. 90, 1628-1634. doi: 10.1021/acs.analchem.7b02883

Pushina, M., and Anzenbacher, P. (2017). Biguanides, anion receptors and sensors. Chem. Commun. 53, 10074-10077. doi: 10.1039/C.7C.C.05012G

Sargenti, A., Farruggia, G., Zaccheroni, N., Marracini, C., Sgarzi, M., Cappadone, C., et.al. (2017). Synthesis of a highly $\mathrm{Mg}^{2+}$-selective fluorescent probe and its application to quantifying and imaging total intracellular magnesium. Nat. Protoc. 12, 461-471. doi: 10.1038/nprot.2016.183

Tan, J., Li, R., and Jiang, Z. T. (2014). Discrimination of fresh fruit juices by a fluorescent sensor array for carboxylic acids based on molecularly imprinted titania. Food Chem. 165, 35-41. doi: 10.1016/j.foodchem.2014. 05.104

Vahter, M., Berglund, M., Akesson, A., and Liden, C. (2002). Metals and women's health. Environ. Res. 88, 145-155. doi: 10.1006/enrs.2002.4338

Wang, M., and Meng, G. (2017). Fluorophores-modified nanomaterials for trace detection of polychlorobiphenyls and heavy metal ions. Sens. Actu. B 243, 1137-1147. doi: 10.1016/j.snb.2016.12.092

Wang, Z., Palacios, M. A., and Anzenbacher, P. Jr. (2008). Fluorescence sensor array for metal ion detection based on various coordination chemistries: general performance and potential application. Anal. Chem. 80, 7451-7459. doi: $10.1021 /$ ac $801165 \mathrm{v}$

World Health Organization (2017). Guidelines for Drinking-water Quality: Fourth Edition Incorporating the First Addendum. Geneva: World Health Organization 2017, 631.

Wu, Y., Liu, X., Wu, Q., Yi, J., and Zhang, G. (2017). Differentiation and determination of metal ions using fluorescent sensor array based on carbon nanodots. Sens. Actu. B 246, 680-685. doi: 10.1016/j.snb.2017.02.132

Wu, Y., Tan, Y., Wu, J., Chen, S., Chen, Y. Z., Zhou, X., et al. (2015). Fluorescence array-based sensing of metal ions using conjugated polyelectrolytes. ACS Appl. Mater. Interfaces 7, 6882-6888. doi: 10.1021/acsami.5b00587

Xu, W., Ren, C.,Teoh, C. L., Peng, J., Gadre, S. H., Rhee,C.-L., et al. (2014). An artificial tongue fluorescent sensor array for identification and quantitation of various heavy metal ions. Anal. Chem. 86, 8763-8769. doi: 10.1021/ac501953z

Zhu, Q., Xiong, W., Gong, Y., Zheng, Y., Che, Y., Zhao, J., et al. (2017). Discrimination of five classes of explosives by a fluorescence array sensor composed of two tricarbazole-nanostructures. Anal. Chem. 89, 11908-11912. doi: 10.1021/acs.analchem.7b04083

Conflict of Interest Statement: The authors declare that the research was conducted in the absence of any commercial or financial relationships that could be construed as a potential conflict of interest.

Copyright (C) 2018 Lvova, Caroleo, Garau, Lippolis, Giorgi, Fusi, Zaccheroni, Lombardo, Prodi, Di Natale and Paolesse. This is an open-access article distributed under the terms of the Creative Commons Attribution License (CC BY). The use, distribution or reproduction in other forums is permitted, provided the original author(s) and the copyright owner are credited and that the original publication in this journal is cited, in accordance with accepted academic practice. No use, distribution or reproduction is permitted which does not comply with these terms. 